УДК 581.1
ВЛИЯНИЕ КЛУБЕНЬКОВЫХ И ПАТОГЕННЫХ БАКТЕРИЙ
НА ИЗМЕНЕНИЕ КОМПОНЕНТОВ АДЕНИЛАТЦИКЛАЗНОЙ
СИГНАЛЬНОЙ СИСТЕМЫ В КОРНЯХ ГОРОХА НА НАЧАЛЬНЫХ
ЭТАПАХ ФОРМИРОВАНИЯ БОБОВО-РИЗОБИАЛЬНОГО СИМБИОЗА

Ищенко А.А.

Сибирский институт физиологии и биохимии растений СО РАН, Иркутск, е-mail: aspt25@yandex.ru

\begin{abstract}
В статье изучена динамика активности растворимой и трансмембранной форм аденилатциклазы (рАЦ и тАЦ), а также циклического аденозинмонофосфата (цАМФ) в корнях этиолированных двухсуточных проростков гороха Pisum sativim L. при взаимодействии с патогенными и клубеньковыми бактериями эффективного и неэффективного производственного штаммов. В краткосрочных опытах (в течение 1 часа с интервалом в 10 минут) обнаружен эндогенный ритм изменения концентрации циклического аденозинмонофосфата в тканях корня проростков гороха, характеризующийся во временной динамике увеличением и снижением уровня цАМФ, который подвержен влиянию экзогенных факторов биотической (симбионт, патоген) природы. Подобные флуктуации также были обнаружены при изучении динамики активности растворимой и трансмембранной форм аденилатциклазы под влиянием тех же биотических факторов. Предполагается, что наблюдаемые эффекты связаны с влиянием на растение определенных экзометаболитов Rhizobium leguminosarum bv. viceae (симбионт) и Pseudomonas syringae pv. pisi (патоген), которые активируют врожденный иммунитет бобового растения. При этом различная динамика изменения изучаемых компонентов сигнальной системы растенияхозяина на начальных этапах взаимодействия с симбиотическими и патогенными микроорганизмами имеет, вероятно, различную функцию: при симбиозе регуляторную, а при патогенезе - защитную.
\end{abstract}

Ключевые слова: Pisum sativum L., аденилатциклаза, циклический аденозинмонофосфат, биотический стресс, сигнальные системы

\title{
INFLUENCE OF STEMEN AND PATHOGENIC BACTERIA ON CHANGE OF THE COMPONENTS OF THE ADENYLYL CYCLASE SIGNAL SYSTEM IN THE PEA ROOTS AT THE INITIAL STAGES OF THE FORMATION OF BEAN-RHIZOBIAL SYMBIOSIS
}

Ishchenko A.A.

Siberian Institute of Plant Physiology and Biochemistry,Irkutsk,e-mail: aspt25@yandex.ru

We studied the dynamics of the activity of soluble and transmembrane forms of adenylate cyclase (pAC and tAC), as well as cyclic adenosine monophosphate (cAMP) in the roots of etiolated two-day-old seedlings of pea Pisum sativim L. when interacting with pathogenic and nodule bacteria of effective and ineffective production strains. In short-term experiments (within an hour with an interval of 10 minutes), an endogenous rhythm of a change in the concentration of cyclic adenosine monophosphate in the tissues of the root of pea seedlings was found, characterized in time dynamics by an increase and decrease in the level of cAMP and which is subject to the influence of exogenous biotic factors (symbiont, pathogen) in nature. Similar fluctuations were also found when studying the dynamics of the activity of the soluble and transmembrane forms of adenylate cyclase under the influence of the same biotic factors. It is assumed that the observed effects are obviously related to the effect on the plant of certain exometebolites of Rhizobium leguminosarum bv. viceae (symbiont) and Pseudomonas syringae pv. pisi (pathogen), which activate the innate immunity of a legume plant. Moreover, the different dynamics of changes in the studied components of the signal system of the host plant at the initial stages of interaction with symbiotic and pathogenic microorganisms probably has a different function: regulatory in case of symbiosis, and protective in case of pathogenesis.

Keywords: Pisum sativum L., adenylate cyclase, cyclic adenosine monophosphate, biotic stress, signaling systems

Патогенные и симбиотические взаимодействия растений с различными группами микроорганизмов часто встречаются в природе и во многом схожи. Они основываются на подавлении или преодолении защитных механизмов растений, что способствует успешной колонизации их клеток. Растения способны реагировать на различные сигналы из внешней среды, приспосабливаясь к ним при помощи генетического аппарата. В свою очередь бактерии, взаимодействуя с растением-хозяином, способны создавать для себя благоприятные условия. В литературе имеются данные о том, что одним из механизмов запуска сигнальных реакций у растений является аденилатциклазная сигнальная система, когда под влиянием различных биотических факторов активируется трансмембранная аденилатциклаза, что вызывает резкое и кратковременное увеличение уровня циклического аденозинмонофосфата $[1,2]$.

Целью настоящей работы было в краткосрочных опытах изучить влияние клубеньковых и патогенных бактерий на отдельные компоненты аденилатциклазной сигнальной системы (цАМФ, рАЦ и тАЦ).

\section{Материалы и методы исследования}

Исследования проводили на проростках гороха (Pisum sativum L.) сорта Рондо, выращенных в термостате при температуре 
$22^{\circ} \mathrm{C}$, у которых в течение часа с интервалом в 10 минут определяли содержание цАМФ, а также активность растворимой и трансмембранной форм аденилатциклазы. В качестве контроля применяли нулевой отрезок времени. Для экспериментов использовали растения, выращенные на воде без инокуляции, а также инокулированные клубеньковыми и патогенными бактериями. Для инокуляции использовали 2 штамма бактериями Rhizobium leguminosarum bv. viceae: эффективный производственный (CIAM 1022), который характеризуется умеренной способностью проникать в корни растений, образуя при этом развитые клубеньки, фиксирующие азот; неэффективный производственный (CIAM 1064), отличающийся более агрессивной способностью колонизировать корневую систему растения-хозяина, что на заключительном этапе формирования бобово-ризобиального симбиоза приводит к образованию большого числа недоразвитых клубеньков, не способных к эффективной азотфиксации; и 1 штамм патогена гороха Pseudomonas syringae pv. pisi, вызывающий бактериальный ожог.

Активность компонентов аденилатциклазной сигнальной системы определя- ли по методу, основанному на работе [3]. Для этого корни фиксировали в жидком азоте и гомогенизировали в среде выделения, содержащей 0,02 М фосфатный буфер, рН 7,2; 0,1 мМ теофиллин; 1 мМ дитиотреитол; 50 мкг/мл фенилметилсульфонилфторид; 50 мкг/мл гидроксимеркурийбензоат; 1 мкг/мл лейпептин. Затем гомогенат центрифугировали 20 мин при 16000 g («Allegra 64 R»). Полученный супернатант центрифугировали 90 мин при 105000 g («Sorvall Discovery 90 SE»). Полученный осадок ресуспендировали и определяли в нем активность трансмембранной аденилатциклазы (тАЦ), а в супернатанте активность растворимой аденилатциклазы (рАЦ) и концентрацию циклического аденозинмонофосфата (цАМФ). Активность аденилатциклаз оценивали по концентрации цАМФ в пробе в пересчете на 1 мг белка. Концентрацию цАМФ определяли иммуноферментным анализом (ELISA). Белок определяли по методу Брэдфорда.

Эксперименты проводили в 3 независимых повторениях. Для лучшего восприятия результаты представлены в процентах от контроля. Достоверность различий оценивали по критерию Стьюдента.

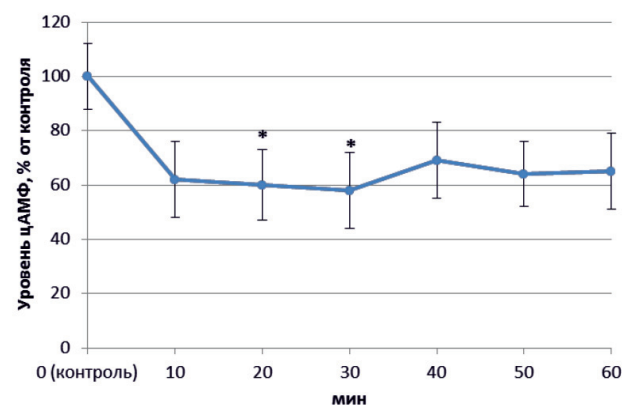

A)

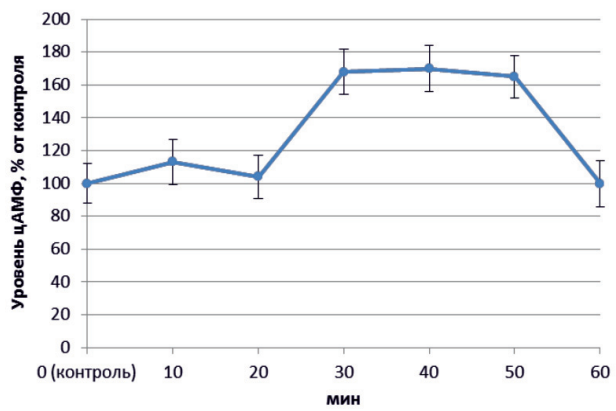

B)

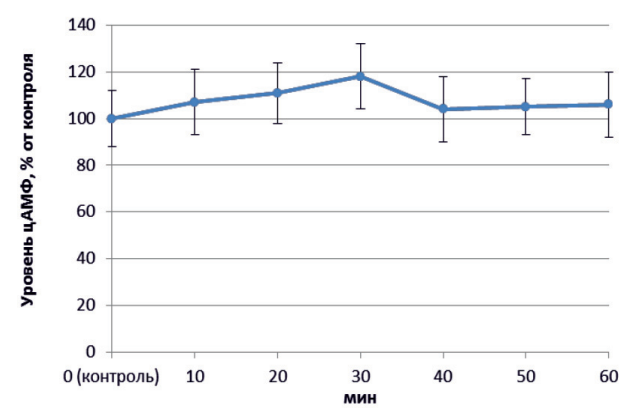

Б)

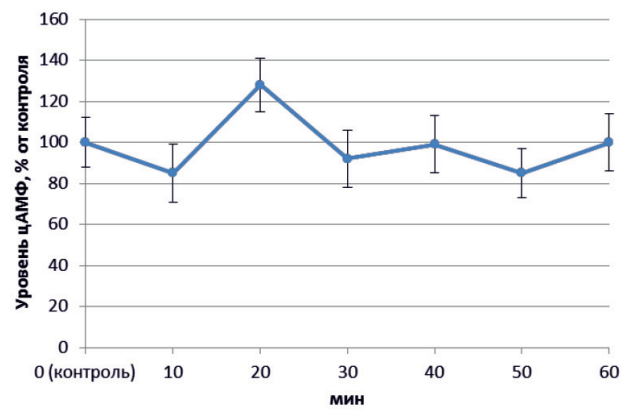

T)

Рис. 1. Динамика уровня иАМФ в корнях проростков гороха: А) выращенных на воде; Б) инокулированных Rhizobium leguminosarum bv. viceae (CIAM 1022); B) инокулированных Rhizobium leguminosarum bv. viceae (CIAM 1064) и Г) зараженных Pseudomonas syringae pv. pisi.

Примечание. *-различия достоверны при $p \geq 0,95$; **-различия достоверны при $p \geq 0$,99; *** - различия достоверны при $p \geq 0$,999; не помеченные «*»-различия не достоверны 


\section{Результаты исследования и их обсуждение}

При выращивании проростков гороха на воде наблюдали снижение уровня цАМФ на протяжении всего эксперимента в среднем на 35-40\% (рис. 1, А).

При добавлении в среду инкубации клубеньковых бактерий эффективного производственного штамма (CIAM 1022) ярко выраженных изменений в концентрации цАМФ не наблюдалось (рис. 1, Б). В свою очередь на фоне инокуляции неэффективным производственным штаммом Rhizobium leguminosarum bv. viceae (CIAM 1064) в период 30-50 минут происходило значительное увеличение уровня цАМФ (на 70\%) (рис. 1, В). При заражении Pseudomonas syringae pv. pisi цАМФ оставался на уровне контроля, за исключением периода 20 минут, когда наблюдалось его увеличение на $30 \%$ (рис. $1, \Gamma$ ).

Из литературы известно, что увеличение концентрации цАМФ внутри клеток при стрессе носит защитный характер и способствует активации соответствующих защитных реакций [2]. В связи с этим повышение концентрации цАМФ под влиянием неэффективного штамма ризобий вполне логично и является механизмом, предотвращающим избыточную колонизацию корневой системы растения-хозяина. Пониженный уровень цАМФ при инокуляции эффективным штаммом клубеньковых бактерий, возможно, также выполняет регуляторную функцию, поскольку уменьшение цАМФ в клетке не приводит к запуску защитных реакций и позволяет ризобиям колонизировать клетки корня. Относительно взаимодействия с PS можно полагать, что пониженный уровень цАМФ свидетельствует о степени вирулентности патогена.

Так как основным источником циклического аденозинмонофосфата является аденилатциклаза, в дальнейших исследования изучали не только уровень цАМФ, но и активность синтезирующих его ферментов (тАЦ и рАЦ).

Изучив активность трансмембранной аденилатциклазы (тАЦ), можно сказать, что во всех вариантах наблюдалась тенденция к увеличению активности изучаемого фермента к 60 минутам (рис. 2).

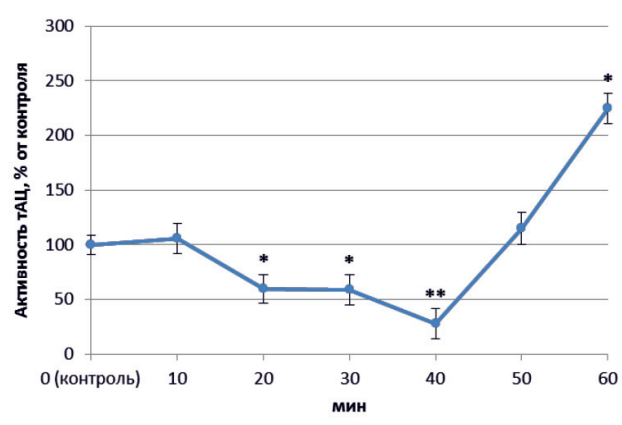

A)

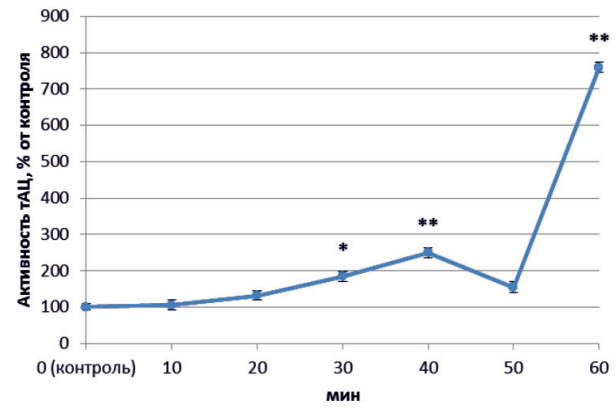

B)

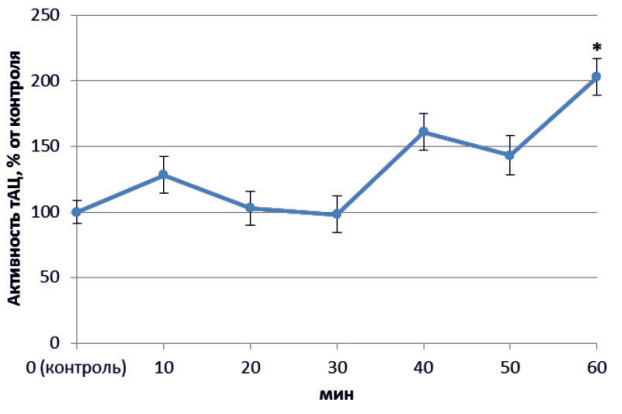

Б)

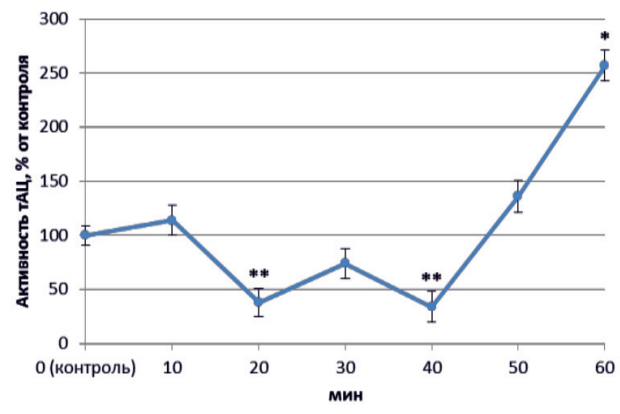

Г)

Рис. 2. Динамика активности тАЦ в корнях проростков гороха: А) выращенныхх на воде; Б) инокулированных Rhizobium leguтinosarum bv. viceae (CIAM 1022); B) инокулированных Rhizobium leguminosarum bv. viceae (CIAM 1064) и Г) зараженных Pseudomonas syringae pv. pisi.

Примечание. *-различия достоверны при $p \geq 0$,95; **-различия достоверны при $p \geq 0,99$; *** - различия достоверны при $p \geq 0$,999; не помеченные «*»-различия не достоверны 


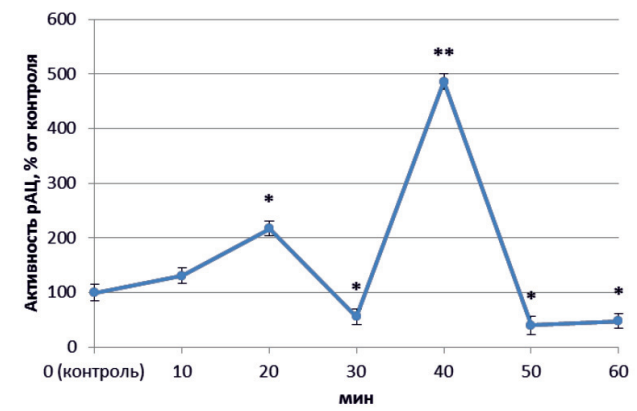

A)

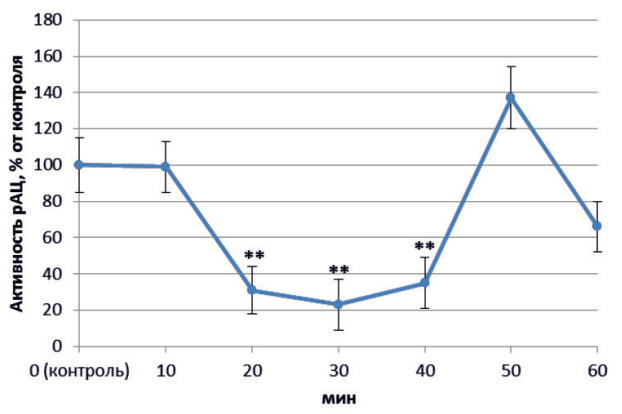

B)

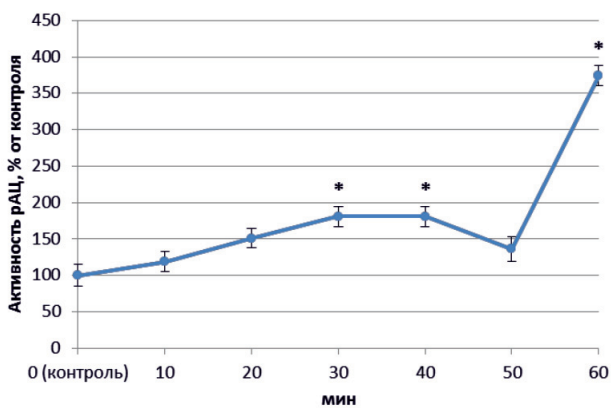

Б)

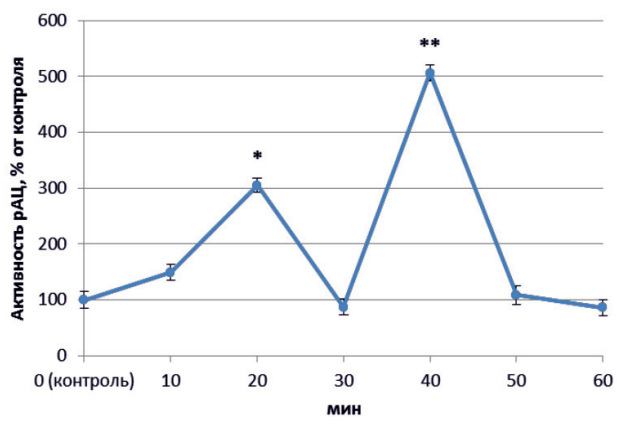

Г)

Рис. 3. Динамика активности рАЦ в корнях проростков гороха: А) выращенных на воде; Б) инокулированных Rhizobium leguminosarum bv. viceae (CIAM 1022); B) инокулированных Rhizobium leguminosarum bv. viceae (CIAM 1064) и Г) зараженных Pseudomonas syringae pv. pisi.

Примечание. *-различия достоверны при $p \geq 0$,95; **-различия достоверны при $p \geq 0$,99; *** - различия достоверны при $p \geq 0$,999; не помеченные «*»-различия не достоверны

Наибольшее увеличение было вызвано неэффективным штаммом клубеньковых бактерий $(650 \%)$ (рис. 2, В), в остальных же вариантах изменение активности составило $100-150 \%$.

В динамике растворимой аденилатциклазы (рАЦ) в норме также определены ритмичные изменения, которые проявлялись в увеличении активности через 20 и 40 минут (на $127 \%$ и $386 \%$ соответственно) и снижении ее до уровня ниже контрольного через 30 и 50 минут на $50 \%$ в обоих случаях (рис. 3, А). Как и в эксперименте с тАЦ, активность рАЦ при взаимодействии с патогеном практически совпадала с контролем (рис. 3, Г). Наибольшие различия наблюдались при инокуляции клубеньковыми бактериями. Так, при взаимодействии с эффективным штаммом ризобий преобладала тенденция к увеличению активности рАЦ, которая к концу эксперимента выросла почти на $350 \%$ (рис. 3, Б). Неэффективный штамм в свою очередь вызывал снижение активности в интервале от 20 до 40 минут (на $50 \%$ ) (рис. 3, В).
Основываясь на данных литературы, можно сказать, что распознавание микросимбионта происходит с участием LysMрецепторных киназ растения-хозяина, которые воспринимают сигналы от экзометаболитов микроорганизмов, в частности экзополисахаридов и Nod-факторов, позволяя сигнальным системам растения реагировать на биотические воздействия $[1,4,5]$. Так, аденилатциклазная сигнальная система, изменяя активность трансмембранной аденилатциклазы - основного источника цАМФ, регулирует метаболические реакции растения при биотических стрессах [6].

Труднее объяснить активность рАЦ в клетках корня гороха. Так как данная форма фермента у растений функционирует во внутриклеточных компартментах, можно предположить, что регуляция ее активности осуществляется посредством внутриклеточного кальция, по аналогии с млекопитающими [2].

Известно, что сигнальные молекулы у растений функционируют взаимосвязанно, на основе чего их можно объединить в сигнальную сеть [7]. В отдельных 
работах указывается, что у растений под влиянием биотических стрессов источником первичных сигналов является цАМФ, поскольку доказано, что под влиянием бактериальных элиситоров в растениях повышается концентрация цАМФ, сопровождающаяся изменениями в концентрациях внутриклеточного $\mathrm{Ca}^{2+}$, который в свою очередь может влиять на уровень оксида азота [6]. Поэтому в дальнейших исследованиях интересно будет изучить влияние экзогенного цАМФ на интенсивность флуоресценции оксида азота в норме и на фоне взаимодействия с клубеньковыми и патогенными бактериями.

\section{Заключение}

Таким образом, по результатам исследований можно отметить следующие закономерности.

1. Под влиянием симбиотических и патогенных бактерий у проростков гороха обнаружены внутриклеточные колебания в уровне циклического аденозинмонофосфата и активности растворимой и трансмембранной форм аденилатциклазы.

2. Можно предположить, что вышеописанные изменения отдельных компонентов аденилатциклазной сигнальной системы растения-хозяина (тАЦ, рАЦ и цАМФ) могут использоваться растениями в качестве кода для передачи сигнала о взаимодействующем факторе.
Работа выполнена при поддержке Российского фонда фундаментальных исследований (молодежный грант № 18-3400221 мол_а).

\section{Список литературы}

1. Глянько А.К., Ищенко А.А. Иммунитет бобового растения, инфицированного клубеньковыми бактериями Rhizobium spp. F. (ОБЗОР) // Прикладная биохимия и микробиология. 2017. Т. 53. № 2. С. 136-145. DOI: 10.7868/ S0555109917020106.

2. Ломоватская Л.А., Кузакова О.В., Романенко А.С., Гончарова А.М. Активность аденилатциклаз и изменение концентрации цАМФ в клетках корня проростков гороха при инфицировании мутуалистами и патогенами // Физиология растений. 2018. Т. 65. № 3. С. 310-320. DOI: 10.7868/ S0015330318040073.

3. Lomovatskaya L.A., Romanenko A.S., Filinova N.V., Dudareva L.V. Determination of cAMP in plant cells by a modified enzyme immunoassay method. Plant Cell Rep. 2011. vol. 30. P. 125-132. DOI: 10.1007/s00299-010-0950-5.

4. Ferguson B.J., Indrasumunar A., Hayashi S., Lin M-H., Lin Y-H., Reid D.E., Gresshoff P.M. Molecular analysis of legume nodule development and autoregulation. Journal of Integrative Plant Biology. 2010. vol. 52. P. 61-76. DOI: 10.1111/j.1744-7909.2010.00899.x.

5. Gough C., Jacquet C. Nod factor perception protein carries weight in biotic interaction. Trends Plant Sciences. 2013. vol. 18. no. 10. P. 566-574. DOI: 10.1016/j.tplants.2013.06.001.

6. Кузакова О.В., Ломоватская Л.А., Романенко А.С. Влияние различных по симбиотической эффективности штаммов Rhizobium leguminosarum bv. viceae на изменение концентрации цАМФ и пероксида водорода в клетках проростков гороха // Физиология растений. 2019. Т. 66. № 5. C. 360-366. DOI: 10.1134/S0015330319050129.

7. Granqvist E., Sun J., den CampR. O., Pujic P., Hill L., Normand P., Morris R.J., Downie J.A., Geurts R., Oldroyd G.E.D. Bacterial-induced calcium oscillations are common to nitrogen-fixing associations of nodulating legumes and nonlegumes. New Phytol. 2015. vol. 207. P. 551-558. 